\title{
Impact of the COVID-19 pandemic in patient admission to a high-complexity cancer center in Southern Brasil
}

\author{
(iD) Jacqueline Justino Nabhen ${ }^{1,2}$ \\ Tayza Katelline Danilau Ostroski 2,3 \\ (D) Milena Massumi Kozonoe ${ }^{2,4}$ \\ (iD) Dinarte Orlandi 5 \\ (iD) Tiago Tormen ${ }^{5}$ \\ Sérgio Ossamu loshii ${ }^{2,4,6}$
}

\begin{abstract}
1. Hospital de Clínicas da Universidade Federal do Paraná, Faculdade de Medicina, Curitiba, PR, Brasil 2. Hospital Erasto Gaertner, Departamento de Anatomia Patológica, Curitiba, PR, Brasil 3. Hospital de Clínicas da Universidade Federal do Paraná, Programa de Pós-Graduação em Medicina Interna e Ciências da Saúde, Curitiba, PR, Brasil 4. Pontifícia Universidade Católica do Paraná, Programa de Pós-Graduação de Tecnologia em Saúde, Curitiba, PR, Brasil 5. Diretor Técnico, Hospital Erasto Gaertner, Curitiba, PR, Brasil 6. Diretor Clínico, Hospital Erasto Gaertner, Curitiba, PR, Brasil
\end{abstract}

http://dx.doi.org/10.1590/1806-9282.66.10.1361

\section{SUMMARY}

OBJECTIVE: The aim of our study was to investigate whether there has been a reduction in patient admission to a high-complexity cancer care center in Brasil during the COVID-19 pandemic, similar to what was reported in Europe.

METHODS: We reviewed the cancer tracking database of the largest cancer center in southern Brasil and performed statistical tests to compare first-time appointments from the onset of the outbreak until the end of June to those of the equivalent period in 2019.

RESULTS: We observed a dramatic reduction (-42\%) in first-time appointments during the pandemic compared to the same period in the previous year $(P<0.001)$. This reduction was observed among all medical specialties $(P<0.001)$.

CONCLUSION: The onset of COVID-19 was correlated with a reduction in admission to a high-complexity cancer care center in Brasil. Since a delay in diagnosis and treatment may influence prognosis, it is important that cancer centers and public health strategies reinforce care for non-COVID-19 patients to prevent potentially unnecessary deaths.

KEYWORDS: Coronavirus Infections. Medical oncology. Delivery of Healthcare. Public Health. Pandemics.

\section{INTRODUCTION}

The coronavirus disease 2019 (COVID-19) has transformed how healthcare is delivered globally and has relegated many medical activities to second priority, oncology included. Cancer care consumes significant healthcare resources, and cancer patients not only are frequently exposed to medical facilities but are also at significant risk for bad outcomes with COVID-19 ${ }^{1,2}$. Due to that, caregivers are forced to make difficult decisions regarding the allocation of limited resources and to weigh the risk from a delay of cancer management versus the harm of COVID-19 exposure ${ }^{3}$. As a possible consequence of this scenario, data from 
European countries showed a significant decrease in cancer referrals and diagnoses during the outbreak ${ }^{4-6}$.

In Brasil, the first case of COVID-19 was confirmed on February 25, and on March 20, the Ministry of Health reported the onset of community transmission of the disease all over the national territory ${ }^{7}$. To slow disease spread, governmental organs advised citizens to stay at home and adopt the social distancing strategy. Despite this measure, more than 1.8 million cases of COVID-19 had been reported by July $13^{8}$. As for the impact of the pandemic on the care for nonCOVID-19 patients, a study suggests a reduction in hospital admission for emergency conditions in Brasil $^{9}$. However, national data of admission to cancer care are lacking in the literature.

In Brasil's Unified Health System (SUS), which provides universal access to healthcare, general practitioners are responsible for referring patients with a suspected cancer diagnosis to High-Complexity Oncology Assistance Units (UNACONs) or High-Complexity Oncology Centers (CACONs) to definite the diagnosis and treatment. The aim of this study was to analyze the epidemiologic impact of the COVID-19 pandemic on admission for high-complexity cancer care in Brasil.

\section{METHODS}

We conducted a single-institution, observational, retrospective study at a CACON located in the city of Curitiba. This CACON is the largest cancer center in southern Brasil and provides care for more than 430,000 patients per year through SUS. We performed a review of its cancer tracking database aimed at evaluating the number of patients newly referred through the public sector who attended a first-time medical appointment in the period between March and June. The same data were also collected for the same period of 2019. We included patients over 18 years old who presented to a non-hematological oncology service. If the same patient was referred to first-time appointments by different medical services, each clinical visit was counted as a different episode. Data was also analyzed in groups according to medical specialty: gastrointestinal/ urogenital, breast, gynecology, head and neck, skin, thoracic, and "other specialties", which included neurology, orthopedy, and ophthalmology services. Data about COVID-19 incidence in Brasil were obtained from official governmental websites ${ }^{8}$. This study was approved by the institutional ethical committee (CAAE 33544820.4.0000.0098).

\section{Statistical analysis}

Data from the pandemic period was compared with that of the equivalent period of 2019 by the Chisquared test and differences with $\mathrm{P}<0.05$ were considered statistically significant. March 20 was chosen as the cut-off date for the statistical analysis because it was the day of the onset of community transmission of COVID-19 in Brasil ${ }^{7}$.

\section{RESULTS}

Overall, from March 20, 2020 to June 30, 2020, 1,002 newly referred patients attended a medical appointment versus 1,717 during the same period last year, which represents 715 fewer patients $(-42 \%)$ (P $<0.001)$. Comparing appointments in 2020 to those in 2019 (Figure 1), respectively, there were 122 versus 196 appointments in the period from 20 to 31 March (-38\%), 278 versus 538 in April (-48\%), 339 versus 501 in May $(-32 \%)$, and 263 versus 482 in June (-45\%). The number of appointments per week decreased in the period between March and June 2020, as the number of COVID-19 cases in Brasil increased (Figure 2). Between March 20 and June 30, a decrease in appointments was observed for all medical specialties (Figure 3): 361 versus 215 for gastrointestinal/urogenital (-40\%) $(\mathrm{P}<0.001), 206$ versus 122 for breast $(-41 \%)(\mathrm{P}<0.001)$, 526 versus 235 for gynecology $(-55 \%)(\mathrm{P}<0.001), 145$ versus 121 for head and neck $(-17 \%)(\mathrm{P}<0.001), 300$ versus 193 for skin $(-36 \%)(\mathrm{P}<0.001), 87$ versus 64 for thoracic $(-26 \%)(\mathrm{P}<0.001)$, and 92 versus 52 for other specialties $(-43 \%)(\mathrm{P}<0.001)$.

\section{DISCUSSION}

The main finding of the present study is the dramatic reduction (42\%) in the number of first-time appointments during the COVID-19 pandemic compared to the same period the year before (Figure 1). A weekly reduction in appointments was observed as the number of COVID-19 cases increased in Brasil (Figure 2). The impact was observed for all medical specialties but was more pronounced for gynecology (Figure 3). Our data is in accordance with previous studies that identified a reduction in overall cancer referrals and in cancer diagnoses during the pandemic in the United Kingdom ${ }^{4,5}$ and in the 


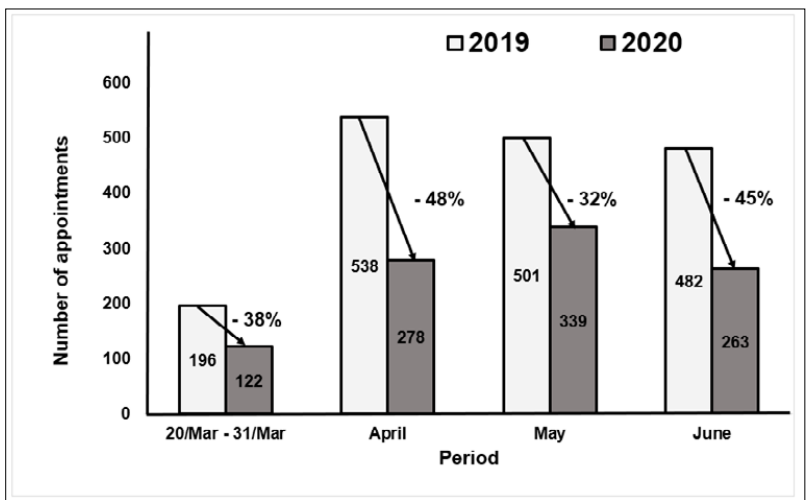

FIGURE 1. NUMBER OF NEW APPOINTMENTS DURING THE COVID-19 PANDEMIC

Number of new appointments during the COVID-19 pandemic in 2020 (darker bars), compared to the same period of 2019 (lighter bars). There was a reduction in apointments in 2020 compared to the equivalent period of 2019.

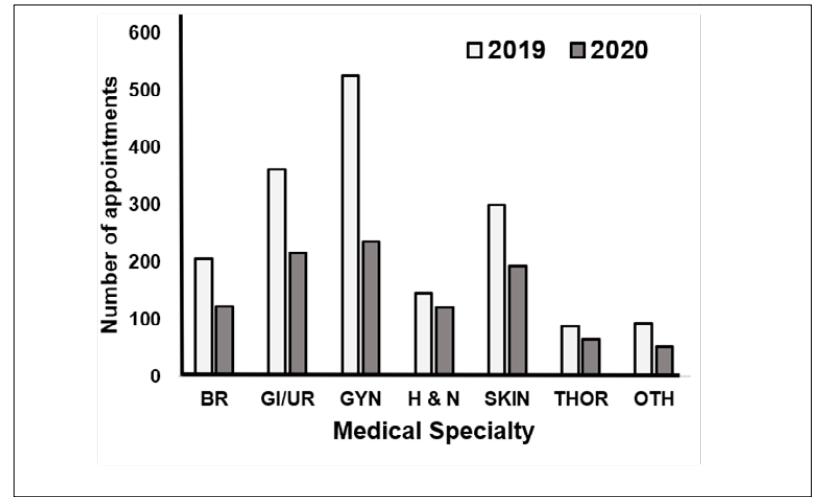

FIGURE 3. NUMBER OF NEW APPOINTMENTS BY MEDICAL SPECIALTY DURING THE COVID-19 PANDEMIC

In 2020 (darker bars) and in same period of 2019 (lighter bars) for comparison. There was a decrease in appointments irrespective of the medical specialty. $\mathrm{BR}=$ breast, $\mathrm{Gl} / \mathrm{UR}=$ gastrointestinal/ urogenital, GYN = gynecology, $\mathrm{H} \& N=$ head and neck, THOR = thoracic, OTH = other specialties.

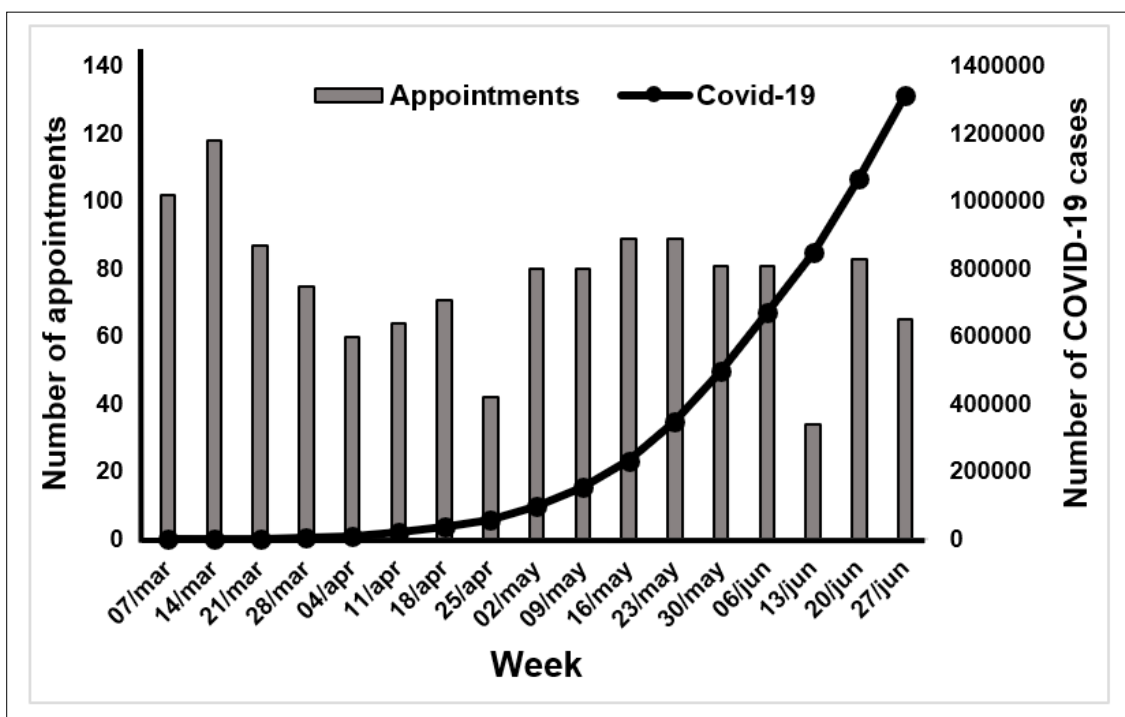

FIGURE 2. NUMBER OF NEW APPOINTMENTS PER WEEK (COLUMNS) IN THE PERIOD BETWEEN MARCH 7, 2020 (END OF CALENDAR WEEK 10) AND JUNE 27, 2020 (END OF CALENDAR WEEK 26) COMPARED TO THE ACCUMULATED INCIDENCE OF COVID-19 IN BRASIL (LINE). THERE WAS A REDUCTION IN WEEKLY APPOINTMENTS AS THE NUMBER OF COVID-19 CASES RAISED IN BRASIL.

Netherlands ${ }^{6}$, countries that have a public health system that provides universal access to healthcare and adopts the gatekeeping principle, similar to the SUS in Brasil.

Identifying the causes that lead to this decrease is beyond the scope of this work; however, we suggest five possible explanations. First, there may have been a reduction in cancer detection among asymptomatic individuals since the National Institute of Cancer in Brasil has issued a recommendation for physicians to postpone cancer screening exams during the outbreak. Second, potential oncology patients may have downplayed symptoms that would otherwise lead them to seek medical attention due to fear of COVID-19 or confusion about stay-at-home orders. Third, general practitioners might have postponed cancer investigations and specialized-center referrals to save healthcare resources for the management of the COVID-19 pandemic. Fourth, the cancer center has postponed appointments considered non-urgent to minimize patient exposure. Fifth, patients may have missed medical appointments at the cancer center due to the anxiety of becoming infected at a healthcare facility. All this combined may explain fewer patients effectively getting specialized oncological care during the pandemic. Of note, despite the remarkable reduction in appointments, there was a period of slight increase and stability during the month of May (Figure 2). We suppose that this is due to a policy adopted by this CACON of using virtual means to contact patients whose appointments could not be postponed. 
Cancer care delay may have a significant impact on the oncological scenario in the near future. Firstly, it is known that some tumors require immediate diagnosis and treatment and that even short delays may impact significantly life expectancy ${ }^{3,10}$. Although other tumors have a lower risk of progression and can tolerate a certain delay in cancer treatment, a model-based analysis showed that a delay of six months in those cases results in a significant amount of cancer-attributable deaths since many of those tumors are common ${ }^{3,10}$. Secondly, postponing cancer care may cause a rebound effect and create an epidemic of cancer cases in the near future, a significant part of them upstaged, which are more expensive to treat. This has a tremendous potential to overwhelm a healthcare system that was already burdened before COVID-19.

Cancer accounts for significant morbimortality and this scenario may be worsened as a consequence of the COVID-19 pandemic ${ }^{11}$. A model estimated additional 6,270 deaths in England and 33,890 in the United States for new cancer cases in 1 year due to the outbreak ${ }^{5}$. In Brasil, cancer is also a major health issue; 626,000 new cases are expected for 2020, and 224,000 deaths were registered in $2018^{12}$. Since the number of COVID-19 cases is still on the rise in our country, cancer management will continue to face challenges and will require individualized decisions based on each patient's condition and each hospital's resources $^{8}$. It is important for cancer centers to set a proactive approach for diminishing patient's exposure to COVID-19 by adapting oncological care during this unusual period, as recommended by national ${ }^{13}$ and international ${ }^{14}$ entities. Contacting patients to minimize their behavior changes towards cancer care is also necessary. In this pandemic context, a rapid and well-structured response is needed, as already reported by institutions in Brasil ${ }^{15}$.

\section{CONCLUSIONS}

In conclusion, our data suggest a significant negative impact of the COVID-19 pandemic in patient admission for cancer care. Its consequences on cancer prognosis and mortality will be evaluated in the near future. As for now, it is important that cancer centers and public health strategies reinforce care for non-COVID-19 patients to prevent potentially unnecessary deaths.

\section{Acknowledgements}

We thank the Hospital Cancer Registry of the Erasto Gaertner Hospital for providing the data used in this study.

\section{Author's Contribution}

Jacqueline Nabhen: conceptualization (Lead), Data curation (Lead), Formal analysis (Lead), Investigation (Lead), Methodology (Lead), Project administration (Lead), Validation (Lead), Visualization (Lead), Writing of the Original Draft (Lead).

Tayza Ostroski; Milena Kozonoe; Tiago Tormen: conceptualization (Supporting), Investigation (Supporting), Methodology (Supporting), Validation (Equal), Visualization (Equal), Review \& Editing (Equal).

Dinarte Orlandi: conceptualization (Equal), Data curation (Lead), Formal analysis (Lead), Methodology (Lead), Validation (Equal), Visualization (Equal), Review \& Editing (Equal).

Sérgio Ossamu Ioshii: conceptualization (Lead), Data curation (Lead), Formal analysis (Lead), Investigation (Lead), Methodology (Lead), Project administration (Lead), Resources (Lead), Supervision (Lead), Validation (Lead), Visualization (Lead), Review \& Editing (Lead).

Institution with which the work is associated: Erasto Gaertner Hospital - Rua Ovande do Amaral, 201, Curitiba, Paraná, Brasil, 81520-060

\section{REFERENCES}

1. Mariotto $A B$, Yabroff KR, Shao Y, Feuer EJ, Brown ML. Projections of the cost of cancer care in the United States: 2010-2020. J Natl Cancer Instit. 2011;103(2):117-28.

2. Kuderer NM, Choueiri TK, Shah DP, Shyr Y, Rubinstein SM, Rivera DR, et al; COVID-19 and Cancer Consortium. Clinical impact of COVID-19 on patients with cancer (CCC19): a cohort study. Lancet. 2020;395(10241):1907-18.

3. Kutikov A, Weinberg DS, Edelman MJ, Horwitz EM, Uzzo RG, Fisher RI. A war on two fronts: cancer care in the time of COVID-19. Ann Intern Med. 2020;172(11):756-8.
4. Earnshaw CH, Hunter HJA, McMullen E, Griffiths CEM, Warren RB. Reduction in skin cancer diagnosis, and overall cancer referrals, during the COVID19 pandemic. Br J Dermatol. 2020;10.1111/bjd.19267.

5. Lai AG, Pasea L, Banerjee A, Denaxas S, Katsoulis M, Chang WH, et al. Estimating excess mortality in people with cancer and multimorbidity in the COVID-19 emergency. medRxiv. 2020.05.27.20083287; doi: https://doi. org/10.1101/2020.05.27.20083287.

6. Dinmohamed AG, Visser O, Verhoeven RHA, Louwman MWJ, van 
Nederveen FH, Willems SM, et al. Fewer cancer diagnoses during the COVID-19 epidemic in the Netherlands. Lancet Oncol. 2020;21(6):750-1.

7. BRASIL. Ministério da Saúde. Ministério da Saúde declara transmissão comunitária nacional. Brasília: Ministério da Saúde; 2020. [cited 2020 June 14]. Available from: https://www.saude.gov.br/noticias/agencia-saude/46568-ministerio-da-saude-declara-transmissao-comunitaria-nacional

8. BRASIL. Ministério da Saúde. Painel coronavírus. Brasília: Ministério da Saúde; 2020. [cited 2020 June 14]. Available from: https://covid.saude. gov.br/

9. Diegoli H, Magalhães PSC, Martins SCO, Moro CHC, França PHC, Safanelli J, et al. Decrease in hospital admissions for transient ischemic attack, mild, and moderate stroke during the COVID-19 era. Stroke. 2020;51(8):2315-21.

10. Sud A, Jones ME, Broggio J, Loveday C, Torr B, Garrett A, et al. Collateral damage: the impact on outcomes from cancer surgery of the COVID-19 pandemic. Ann Oncol. 2020;31(8):1065-74.
11. Bray F, Ferlay J, Soerjomataram I, Siegel RL, Torre LA, Jemal A. Global cance statistics 2018: GLOBOCAN estimates of incidence and mortality worldwide for 36 cancers in 185 countries. CA Cancer J Clin. 2018;68(6):394-424.

12. Instituto Nacional de Câncer. Estatísticas de câncer. [cited 2020 June 14] Available from: https://www.inca.gov.br/numeros-de-cancer.

13. Sociedade Brasileira de Oncologia Clínica. Posicionamento SBOC - Coronavírus (COVID-19): informação ao paciente. São Paulo: Sociedade Brasileira de Oncologia Clínica; 2020. [cited 2020 June 14]. Available from: https://sboc. org.br/noticias/item/1797-posicionamento-sboc-coronavirus-COVID-19

14. American Society of Clinical Oncology (ASCO). ASCO coronavirus resources. Alexandria: American Society of Clinical Oncology; 2020. [cited 2020 June 14]. Available from: https://www.asco.org/asco-coronavirus-information/ care-individuals-cancer-duringCOVID-19

15. Sternberg C, Andrade TL, Nova APGAV, Fiscina BV, Fernandes APL, Alves CD, et al. Oncology practice during COVID-19 pandemic: a fast response is the best response. Rev Assoc Med Bras. 2020;66(3):338-44. 